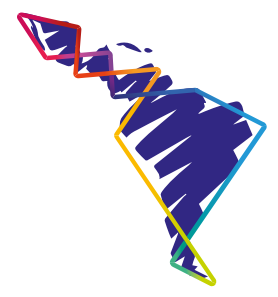

\title{
La Concepción Tetradimensional del Derecho, como propuesta Epistemológica para la garantía de los Derechos Humanos
}

\section{The Tetradimensional Conception of Law, as an Epistemological Proposal for the guarantee of Human Rights}

\author{
A Concepção Tetradimensional \\ de Direito, como proposta \\ Epistemológica de garantia dos \\ Direitos Humanos
}

Enrique Uribe Arzate ${ }^{1}$

\begin{abstract}
Resumen
La concepción del derecho influye decisivamente en la garantía de los derechos humanos. La teoría tridimensional del derecho ha vinculado norma, hecho y valor para expresar que el derecho no se puede entender de forma monolítica o unidimensional; con base en esta teoría, los derechos humanos no se concretan en la vida cotidiana de las personas, pues, a la teoría en cuestión le hace falta el elemento político. Por eso, es necesario construir una teoría tetradimensional que incluya al derecho como política y, concretamente, como políticas públicas para la garantía eficaz de los derechos humanos. El objetivo de este trabajo es mostrar la pertinencia de la visión tetradimensional del derecho para la identificación de la política en la búsqueda de mecanismos a favor de la garantía de los derechos humanos.
\end{abstract}

Recibido: 2-8-2020 • Aceptado: 13-5-2021

1 Doctor en Derecho por la Universidad Nacional Autónoma de México. Profesor de tiempo completo en la Facultad de Derecho de la Universidad Autónoma del Estado de México. Miembro del Sistema Nacional de Investigadores del CONACYT. Correo electrónico: vercingtx@hotmail.com

(D) http://orcid.org/0000-0003-2381-232X 
Palabras clave: Derecho, teoría, derechos humanos.

\begin{abstract}
The conception of the law has a decisive influence on the guarantee of human rights. The three-dimensional theory of law has coupled norm, fact and value to express that law cannot be understood in a monolithic or one-dimensional manner; based on this theory, human rights are not materialized in people's daily lives, since current theory lacks the political element. Thus, it is necessary to build a four-dimensional theory that includes law as policy, specifically, as public policies for the effective guarantee of human rights. The objective of the present work is to exhibit the relevance of the four-dimensional vision of law for the identification of politics in the search for mechanisms in favor of the guarantee of human rights.
\end{abstract}

Keywords: Law; Theory; Human rights.

\title{
Resumo:
}

A concepção do direito tem influência decisiva na garantia dos direitos humanos. A teoria tridimensional do direito vinculou norma, fato e valor para expressar que o direito não pode ser entendido de forma monolítica ou unidimensional; com base nessa teoria, os direitos humanos não se materializam no cotidiano das pessoas, pois a teoria em questão carece do elemento político. Por isso, é necessário construir uma teoria tetradimensional que inclua o direito como política e, especificamente, como políticas públicas para a garantia efetiva dos direitos humanos. O objetivo deste trabalho é mostrar a relevância da visão tetradimensional do direito para a identificação da política na busca de mecanismos em prol da garantia dos direitos humanos.

Palavras-chave: Direito; Teoria; direitos humanos.

\section{La cuestión epistemológica}

Las cuestiones concernientes a los derechos humanos se enfrentan a un enorme desafío de corte epistemológico, debido a las graves limitaciones que se advierten en los afanes que cotidianamente se realizan para su garantía ${ }^{2}$. Como es sabido, gran parte de esos obstáculos se identifican en la lejanía que el discurso y las normas sobre derechos humanos tienen con las condiciones de la realidad. Esta situación coloca a los derechos humanos en la ruta de lo irrealizable y, por ello, resulta pertinente que, en su concepción más adecuada, los principios y postulados que se esgrimen en el discurso sobre la cuestión deban tener un anclaje situado en

2 Este trabajo deriva del proyecto de investigación "La concepción tetradimensional del derecho para la garantía de los derechos humanos en el estado constitucional”, clave 3800/14CIA, financiado por la Universidad Autónoma del Estado de México

Hemos referido reiteradamente que "derechos humanos sin garantías, es una aporía”. Este es el enorme desafío de los derechos humanos, debido a que ni el discurso ni las normas son suficientes para asegurarlos 
la realidad y en la viabilidad de lo defendible que, sin duda, alimente todo lo que practica y dice sobre los derechos humanos.

En este orden de ideas, la construcción hasta ahora lograda de los derechos humanos se encuentra basada -de manera destacada- en los trazos tradicionales del positivismo, pues el discurso sobre este tópico está fuertemente condicionado por las posibilidades que el lenguaje jurídico alcanza a prescribir en forma de proposiciones. "Cuando decimos que una norma jurídica es una proposición, queremos significar que es un conjunto de palabras que tienen un significado" (Bobbio, 1992, p. 57). De este modo, la percepción cotidiana sobre el discurso y el contenido de los derechos humanos necesita valerse del lenguaje jurídico especializado que utiliza categorías ad hoc para su uso en este campo. Así, por ejemplo, las voces "interés superior del menor", "principio pro-persona", "grupos vulnerables", "protección multinivel", son palabras y expresiones que se utilizan de forma concreta en las tareas de protección de los derechos de los habitantes.

De este modo, todo lo que se puede decir de los derechos humanos está, necesariamente, anotado en textos jurídicos; en este orden de ideas, las posibilidades de apropiación de esos derechos prescritos en la norma positiva e, incluso, la propia proyección que se puede tener sobre su acrecentamiento y vivencia, dependen definitivamente de lo que los textos legales puedan ofrecer a los habitantes. "El derecho como ciencia, tiene su propio lenguaje. El jurista utiliza expresiones quizás inusuales para el ciudadano común, por no estar vinculado con la ciencia jurídica" (Lastra, 2002, p. 162). Por ello, la lectura de los derechos humanos está, en alguna medida, condicionada por el lenguaje especializado que los contiene y expresa.

Como es posible advertir, esta concepción legalista o, mejor dicho, positivista de los derechos humanos, enfrenta el ingente desafío que implica pasar de la prescripción normativa a la realidad; esta cuestión, en sí misma difícil de lograr, patentiza la fragilidad e insuficiencia de una concepción monolítica-positivista de los derechos humanos. Desde luego, en esta concepción, el lenguaje jurídico especializado tiene una importancia de primer orden, pues, gracias a su estructura y morfología, es posible subir al discurso de las normas los "contenidos", o al menos las pretensiones, de los contenidos de los derechos humanos.

Ante este reto que el formalismo no ha podido atender suficientemente, diversas interpretaciones han permitido entender los derechos humanos desde otras proyecciones que los pretenden vincular indefectiblemente con la realidad; es decir, comienza a ser más insistente la idea de que la existencia de los derechos humanos es mucho más que su manufactura tradicional en normas de derecho positivo. 
"En muchos campos de la realidad como el de la trata de personas, la desnutrición de multitudes, incluyendo niños, el creciente desempleo, la destrucción del ambiente y otros, nos enfrentamos a un avanzadísimo derecho positivo y una espeluznante realidad" (Camacho, 2016, p. 4). Es claro, entonces, que el desiderátum de los derechos humanos de orden positivo necesita su anclaje en la realidad; de lo contrario, las proyecciones de la norma carecen de viabilidad y sentido.

Desde otro promontorio también se pretende pergeñar los derechos humanos, ya no solo en la lectura de las normas legales, ni en las posibilidades de su aprehensión en la realidad, sino de manera preponderante en su asiento más hondo que, innegablemente, se sitúa en los fundamentos metanormativos que a lo largo del tiempo han permitido decir que el ser humano es un ente autoteleológico. Con esto, se cree posible regresar a un planteamiento esencialmente filosófico que concede a la visión axiológica un lugar preeminente. De este modo, para hablar de los derechos inmanentes al ser humano, se cree que como última ratio es debido volver la mirada al concepto de dignidad humana.

De acuerdo con Marín (2014):

La dignidad humana indica, primero, la capacidad (apoderamiento) de quien la posee para actuar de forma autónoma en pro del ideal de perfeccionamiento humano; $\mathrm{y}$, en segundo término, el camino que debe seguir dicha actuación, que no puede ser cualquiera (restricción), pues ha de conducir a un lugar determinado. (p. 26)

Ante esto, cualquiera de estos tres modos de abordar la comprensión de los derechos humanos tiene sus propias limitaciones. Lo cierto es que la tesis predominante de orden normativo formal-positivista sigue siendo el espacio de consulta obligada para cualquiera que desee conocer qué son los derechos humanos, cuáles son sus contenidos y cómo es posible arribar a su apropiación y disfrute. En este punto en concreto está uno de los mayores desafíos en este campo: Los derechos humanos deben dar paso a un obligado giro hermenéutico y a ejercicios heurísticos que nos puedan llevar a la identificación de estas cualidades o prerrogativas inescindibles de la naturaleza humana, con independencia del "estado" que guarde el orden jurídico positivo de una sociedad determinada.

Desde luego, en esta cuestión posee gran importancia la capacidad humana para la construcción de escenarios que estén contenidos tanto en corpus de orden nacional como internacional. Resulta innegable que el lenguaje (finalmente creación humana) no puede ser soslayado en la importante labor de redactar con puntualidad y pulcritud qué son los derechos humanos y cómo es posible acceder a su vivencia cotidiana. En este orden de ideas, es oportuno afirmar que no podemos sustraernos 
de esta función capital que tiene el lenguaje jurídico especializado y, por tanto, uno de los mayores retos en la actualidad se ubica en encontrar la senda accesible, viable y cierta para que todo derecho humano descrito en cualquier corpus del ámbito que sea tenga posibilidades de ser aprehendido, apropiado y vivenciado.

Según Lastra (2002):

Por tanto, sabemos el riesgo que entraña para el jurista que trabaja de manera preferente con las normas válidas, de un determinado ordenamiento jurídico, cuando éstas desajustan con la realidad social. Porque, entonces será difícil aplicarlas en forma satisfactoria para resolver los conflictos actuales de intereses en la sociedad. En tal sentido, debemos tener la precaución de expurgar, de nuestros textos legales, todo aquello que esté superado por la práctica y así evitar normas "moribundas" o "letra muerta", en las disposiciones jurídicas. (p. 166)

En vista de lo hasta aquí planteado, resulta pertinente el abordaje de esta cuestión de orden fundamental, con la finalidad de intentar un desarrollo epistemológico que permita la construcción de mejores escenarios, condiciones, mecanismos e instrumentos para que el discurso de los derechos humanos trascienda de las normas del derecho positivo a su materialización en la vida cotidiana de los habitantes. Para tal fin, nos serviremos de un análisis conceptual y teórico de los derechos humanos, tomando como referencia la teoría tridimensional del derecho de Miguel Reale, y a través de ella intentar una construcción epistemológica que haga posible una mejor comprensión de los referidos derechos, a favor de una posible conexión con su apropiación y disfrute.

Con estos señalamientos preliminares, a partir del abordaje del "estado del arte" sobre los derechos humanos, trataremos de engarzar su explicación desde la teoría tridimensional del derecho que explica la proyección normativa, fáctica y axiológica de lo jurídico; desde ahora, es posible declarar que el presente esfuerzo de orden hermenéutico procura esta aproximación epistemológica con el propósito central de lograr que las normas jurídicas, contenidas en el discurso de los derechos humanos, se ensamblen con la realidad y, al mismo tiempo, apelen a valores superiores que el lenguaje especializado no debe soslayar.

Por tal razón, parece oportuno plantear un ejercicio de indagación que nos lleve a comprender los derechos humanos en la triple proyección derivada de la teoría tridimensional del derecho, para plantear, en el centro de la cuestión, las alternativas epistemológicas que nos puedan conducir a una proyección más cercana, accesible y efectiva para el disfrute de los derechos humanos. Sobre este enorme desafío, 
ni siquiera el plano normativo superior del Estado está exento de esta valoración inexcusable. Sobre esta idea, Bachof (2008) señala:

La pregunta acerca de la validez de una Constitución se apoya, en general, sólo en su legitimidad y no su legalidad. Sería, de hecho, poco significativo, querer hacer depender la validez de una Constitución de su "legalidad" en el sentido de su aprobación conforme a las prescripciones de la Constitución anteriormente válida. (p. 54)

\section{Una visión tridimensional del derecho}

No cabe duda que la comprensión de los conceptos clave del derecho es una de las tareas que todo jurista debe emprender, puesto que de la comprensión cabal, científica e inequívoca de estos conceptos clave depende la configuración del derecho y el tratamiento exitoso de las cuestiones que en él se contienen.

Una de las palabras clave que debe ocupar la atención de toda persona que ejerce una profesión jurídica es, justamente, la voz jurídico, ya que de esta expresión deriva y en ella está anclado todo el derecho que, como ciencia y como objeto de estudio, es posible abordar. Hasta ahora, damos por sentado que la expresión jurídico hace referencia al derecho y a todo lo que esta segunda expresión puede incluir; sin embargo, la voz jurídico, tiene una lamentable inexactitud y multivocidad que, en el mejor de los casos, se soluciona con una postura axiomática que simplemente lo hace coincidir con la voz derecho.

Desde esta proyección, el análisis de lo jurídico representa el primer gran esfuerzo que cualquier jurista debe hacer para poder determinar qué cuestiones de la vida humana es posible incluir y comprender en esta expresión. En este punto, García Amado (1992) se refiere a lo jurídico como una referencia a estas tres posibilidades:

Implicación vivencial ordinaria. Llamo así a la percepción general que de lo jurídico tienen los miembros de una sociedad, como orden que se les impone y en que están insertos. (...) Implicación operativa o práctica. Es el tipo de conocimiento de lo jurídico que aparece en los $<$ aplicadores $>$ del derecho u operadores jurídicos organizados, es decir, en quienes < pronuncian $>$ el derecho con efectos prácticos inmediatos de mayor o menor alcance (jueces, abogados, legisladores, notarios, burócratas (...). Conocimiento teórico del derecho. Aquí se trataría de aquellos conocimientos del derecho, que supuestamente no irían dirigidos a pronunciar el derecho, sino a pronunciarse sobre el derecho, preferentemente en clave analítica y descriptiva. (pp. 200-201) 
En términos concretos, lo que una sociedad vive como derecho, lo que la práctica de los operadores jurídicos dice como derecho y lo que los estudiosos afirman desde la doctrina y la teoría como derecho, es lo que dimensiona el contenido de lo jurídico. Esta es una aproximación primaria a la esencia de lo jurídico que, hasta ahora, no tiene una definición única o al menos una comprensión univoca. Por esta razón, resulta fundamental aventurar desde ahora y para los efectos del presente estudio que la voz jurídico -aplicable a cualquier ámbito de aplicación del derecho- desborda desde luego la manufactura positivista de la ley, los alcances interpretativos de la jurisprudencia y hasta las tareas de complementariedad que se realizan por la vía de la integración. Id. est., con la voz jurídico, toda referencia al campo del derecho toca la parte esencial que define y alimenta este campo del conocimiento humano, con lo cual queremos decir que, según la presente perspectiva, lo jurídico es la dimensión humana de la justicia que se proyecta como la savia vital que alimenta, da forma y contenido a todo aquello que cualquier persona, especialista o no, pueda decir, entender o expresar como derecho.

$\mathrm{Al}$ respecto, una de las tesis que mejor han explicado esta cuestión es la teoría tridimensional del derecho, donde Miguel Reale sostiene que el derecho se puede comprender como norma, como hecho y como valor. Para los efectos del presente trabajo, la referencia a esta postura tiene la intención de realizar un ejercicio comparativo para poder otear los alcances de la aproximación epistemológica a los derechos humanos, a partir de esta triple concepción de estos como norma, realidad y valor.

Al respecto, dijo Reale (1997):

Es menester no olvidar que la comprensión del derecho como $<$ hecho histórico-cultural $>$ implica el convencimiento de que estamos ante una realidad esencialmente dialéctica, es decir, que no es concebible sino como processus, cuyos elementos o momentos constitutivos son hecho, valor y norma al que doy nombre de $<$ dimensión> en sentido, evidentemente, filosófico y no físico-matemático. (p. 85)

Por ende, la conexión entre lo jurídico (como esencia del derecho) y las tres posturas aquí citadas para la comprensión de lo que llamamos derecho, arrojan frente al investigador tres diferentes maneras de abordar los fenómenos que se pueden identificar como derecho y, a partir de la ubicación de estas tres posibilidades, tanto la "lectura" del derecho, como sus posibilidades y resultados, difieren sensiblemente. Ergo, la idea de que el derecho es norma o tiene la textura y posibilidades de toda norma jurídica, está decisivamente condicionada por lo que la teoría de las normas pueda decir al respecto. Ante esto, si las normas están determinadas por conceptos clave como la existencia o validez, la generalidad, abstracción e 
impersonalidad, así como por su bilateralidad y naturaleza vinculante, como lógica consecuencia, es viable decir que, de no atender estas reglas esenciales, el derecho no puede ser configurado como tal. En consecuencia, los dos círculos restantes de la teoría tridimensional (hecho y valor) son inadmisibles.

Sobre este punto, es prudente afirmar que la concepción del derecho como norma apela al tiempo, a la formalidad y a la existencia, como reglas esenciales implicadas en la gestación de lo jurídico-positivo.

La mayoría de las normas comienzan a existir y dejan de existir en el curso del tiempo. Pueden iniciar a través de un acto de emanación o promulgación por parte de alguna "autoridad normativa", y dejar de existir a través de un acto de eliminación o derogación (Von Wright, 1997).

Incluso, vale agregar que la construcción del derecho, desde esa proyección rígida, rigurosa y formal, exige el cumplimiento de otras reglas prescritas desde la lógica y los modos de construcción de las proposiciones que contienen el referido derecho. "Una norma válida, es decir provista de la fuerza obligatoria, existe de manera análoga a aquella cuya existencia es una proposición afirmada" (Kalinowski, 1996, p. 21).

En seguimiento de estas reflexiones, se debe resaltar la visión del derecho como expresión de tipo factual: si el derecho se asume como una manifestación de fenómenos de la realidad, el registro de estos fenómenos en textos legales es un asunto de orden secundario y, en todo caso, accesorio no determinante de la existencia de ese derecho. Los contextos de cada tradición jurídica, marcan, como es sabido, distintas maneras de construcción de derecho. De tal modo, la positivización de leyes a través del proceso legislativo es un asunto esencial en los países que fueron modelados bajo la tradición romano-germano canónica; en cambio, en los países del common law, los procesos son diferentes y se encuentran mayormente vinculados a la costumbre y a los modos en que la sociedad expresa lo jurídico en sus actividades cotidianas.

El estudio del derecho no parece, de ningún modo, una disciplina intelectual; por otro lado, este estudio forma parte de una práctica que habría de ser el objeto mismo de estudio. Desde el principio mismo, el estudio del derecho es cooptado por la práctica jurídica (Kahn, 2001).

Lo anterior señala la visión del derecho como hecho, con lo cual posee un significado particular en los países del common law y, aún en estos, la realidad que va modelando paulatinamente el derecho a través del sistema de precedentes requiere 
que la decisión del juez concluya esa construcción legal a través de su sentencia. Como es posible observar, ni siquiera en estos sistemas jurídicos, la realidad se impone en automático como la gran fuerza modeladora de derecho. De cualquier forma, destaca en esta aproximación teórica la relevancia indiscutible de los hechos, más allá de lo que las normas positivadas puedan decir a través del lenguaje jurídico que integra los artículos de los corpus legales.

En tercer lugar, la tesis comentada sostiene que el derecho es valor. Este tercer circulo nos conduce a una zona de mayor dificultad, pues un derecho de orden axiológico per se, resulta difícil de concebir. La idea central en este punto establece que el derecho es más que normas legales y algo distinto a los hechos que expresan una cuestión jurídica. Las leyes positivas del Estado tienen una aprehensión inmediata, en cuanto basta con leerlas en algún corpus para entender que, lo que yace escrito ahí, es derecho. Los hechos que se admiten como derecho, si bien no lo necesitan, están prescritos previamente como derecho en algún corpus, se configuran como una manifestación de orden "jurídico" por los efectos o las consecuencias que se gestan a partir de la consumación de ese hecho; típicamente, se cita al nacimiento y a la muerte como hechos de contenido "jurídico". Desde luego, ambos están previstos en el derecho como norma; aun así, hay casos en los que el derecho escrito no puede prever y que, por la fuerza de lo fáctico, deben ser situados como derecho nuevo emanado de los fenómenos de la realidad. $V g r$., hoy que la pandemia propiciada por el virus covid-19 ha atemorizado al mundo entero, seguramente la igualdad real entre seres humanos comenzará a configurarse a fortiori como un concepto jurídico que de inmediato desbordará la idea de igualdad legal que encierran los textos de las leyes. Del mismo modo, en el caso del derecho laboral, el hecho de tener que trabajar desde casa, supondrá modificar en las leyes conceptos clásicos como la jornada de trabajo (ahora no sabemos si el home office pertenece a la jornada diurna, nocturna o mixta), o las horas extras (que ahora no sabemos cómo se deberán computar).

Ergo, el tercer circulo que admite al derecho como un valor, sostiene que ninguno de los otros dos espacios previamente analizados puede ser concebido sin la inmediata alusión a principios y valores que alimentan y estructuran tanto al discurso del derecho contenido en las leyes, como a los hechos que deben "tener" el aspecto jurídico para poder ser referidos como eventos que interesen al derecho. De este modo, el derecho como valor vive en los conceptos meridianos de igualdad, libertad, justicia, respeto, tolerancia, no discriminación; estos valores son derecho, según la tesis de Reale al margen de que las leyes los contengan o no y con independencia de que las manifestaciones de orden factual aludan a ellos o ni siquiera los mencionen; en el primer caso, el derecho como norma (sin 
valores) será un derecho injusto; en el segundo supuesto, el derecho como hecho (sin valores) será una burda imposición.

A partir de estas breves reflexiones sobre la teoría tridimensional del derecho, se intentará configurar la concepción de los derechos humanos, más próxima a su concreción.

\section{Realidad y valores en derechos humanos}

Luego de la exploración sobre los diferentes modos de comprender las manifestaciones de lo jurídico, es pertinente adentrarse en los modos de concreción, operación y aplicabilidad de los derechos humanos. Esta cuestión, que sin duda tiene un gran fondo teórico, resulta fundamental para poder intentar la conexión entre el discurso de los referidos derechos y las posibilidades reales de su garantía efectiva.

Como ya se mencionó, la teoría tridimensional nos ha mostrado que las manifestaciones humanas, englobadas bajo la denominación derecho y lo jurídico, representan tres perspectivas distintas para la aprehensión de estas complejas manifestaciones de carácter humano-social. En este orden de ideas, todas las expresiones que se pueden comprender bajo el dosel de los derechos humanos, por principio, son visibles a partir de la lectura que es posible hacer de los textos jurídicos que los contienen y describen; empero, no es esta la única manera (y creemos que no debe serlo) de aproximarnos al entendimiento de lo que bajo el concepto derechos humanos es posible visibilizar.

A partir de esta idea central -siguiendo la teoría tridimensional del derecho- la expresión derechos humanos tiene una lectura primigenia de orden legal positivo, esto es, la primera experiencia que todo ser humano puede tener sobre lo que se dice de sus derechos solo es posible por la vía de la lectura de lo que los textos legales tienen inscrito en sus diversos artículos. Por nuestra parte, postulamos que este acercamiento primigenio a los derechos humanos, naturalmente de orden normativo, deja fuera muchos otros elementos que son indispensables e insoslayables en la vida humano-social para la forja y el florecimiento de los derechos humanos en la sociedad actual.

Desde esta perspectiva inicial, y tomando como referencia la teoría tridimensional multicitada, el circulo que corresponde al derecho como norma equivaldría a una concepción legal-positivista de los derechos humanos, aprehensible tan solo en la medida y las posibilidades que el lenguaje jurídico especializado es capaz de ofrecernos en los distintos corpus sobre esta materia. 
Resulta lógico sostener que esta visión monolítica-positivista de los derechos humanos es a la vez su mejor carta de presentación desde la condición y exigencia de la seguridad jurídica, pero también su más limitada manifestación en texto, porque entonces los derechos se entienden cumplimentados, en cuanto la redacción es más adecuada, descriptiva e incluso prescriptiva desde un punto de vista deontológico. Con esto se quiere decir que, si los derechos humanos pertenecen o se limitan solamente al primer círculo de orden formal positivista, el estado cumple cabalmente con ellos (en términos estrictamente formales) en la medida que una mejor redacción y una mayor puntualidad en la descripción de esos derechos permite su apropiación, así sea solo formal, desde su incorporación en los textos legales de cualquier orden jerárquico.

Como se puede advertir, la insuficiencia de esta mirada monolítica sobre la concepción de los derechos humanos es evidente. Por tal razón, al trascender al segundo círculo de la teoría tridimensional en cita, los derechos humanos como realidad, superan y desbordan las descripciones de orden normativo contenidas en los instrumentos jurídicos de la materia. Una aproximación epistemológica a partir de esta concepción de orden pragmático deja al descubierto una evidente "imposibilidad formal" para la aprehensión del significado y alcances de los derechos humanos desde una mirada metanormativa. Id. est., resulta sumamente difícil argumentar la existencia de algún derecho humano que no haya sido previamente escrito en lenguaje jurídico especializado y se encuentre contenido en un corpus formalmente sancionado por los órganos competentes del poder público; afirmar lo contrario, representa uno de los mayores desafíos de la doctrina sobre los derechos humanos que, desde luego, tiene trazos metanormativos y metajurídicos porque se instala en otras parcelas del conocimiento como la sociología y la antropología, por citar solo dos de las más visibles en lo inmediato.

En lo que aquí se abarca, resulta factible argumentar que más allá de la descripción y prescripción normativa, los derechos humanos tienen una profunda raigambre en las sociedades tan complejas, distintas y multiétnicas que hoy pueblan la tierra. Con tal afirmación, cualquier alegato esgrimido por el multiculturalismo daría paso al ahogamiento de las normas jurídicas de orden positivo, estrechas y limitadas en sí mismas. Al decir esto, el círculo que corresponde a la visión de orden social lleva a entender que los derechos humanos existen o preexisten incluso al margen de su redacción formal en textos jurídicos. De tal postulado, salta a la vista la dificultad que conlleva la compresión de los derechos humanos desde la dimensión factual para intentar darles forma y un lenguaje jurídico apropiado para su "incorporación" y/o "reconocimiento" en los distintos corpus de la materia. Hasta hora, esta dificultad epistemológica no ha sido zanjada. 
Existe una casi insalvable línea divisoria entre los dos círculos ya analizados que corresponden a los derechos humanos como norma y los derechos humanos como realidad. La teoría tridimensional, descrita en el presente análisis, muestra un tercer circulo que corresponde a la dimensión axiológica de los derechos humanos. En este contexto, ni la ley ni las cuestiones de orden factico representan las únicas manifestaciones de los derechos humanos, en cuanto a que estos se alimentan y así han sido concebidos desde su origen, de principios y valores que les dotan de contenido y forma. Dicha forma y contenido de cualquier derecho, no se pueden explicar adecuadamente sin la alusión inmediata a voces como libertad, seguridad, igualdad, no discriminación, hasta llegar a la raíz más profunda donde reside el concepto dignidad.

¿Hasta dónde es posible aludir a los derechos humanos prescindiendo de estos elementos de carácter valorativo? La respuesta no parece sencilla, pues, como se ha delineado en los párrafos precedentes, la mirada inicial sobre estos derechos no se puede hacer fuera del lenguaje especializado que los define y describe en textos legales, así como tampoco representa un ejercicio sencillo intentar vincular esas prescripciones de orden normativo con las manifestaciones de orden fáctico que igualmente pueden "contener" derechos humanos.

Con estas referencias es posible sostener que una adecuada concepción de los derechos humanos tendría que realizar la conexión entre los tres círculos que corresponden a tres perspectivas para la comprensión de los derechos humanos. Desde luego, queda claro que cualquier visión monolítica en este campo resultará insatisfactoria por las limitaciones inminentes a su propia naturaleza. A mayor profundidad, se entiende que la visión monolítica de orden positivo poco sirve a los seres humanos si no traspasa el contexto de las normas y se instala en la realidad; por su parte, la visión monolítica de orden factual pocas expectativas tiene específicamente en cuanto a su "garantía", debido a la imprecisión, volatilidad y casuismo que "naturalmente" acompañan a cualquiera de estas manifestaciones visibles en las expresiones de cada sociedad, de cada pueblo y de cada cultura.

En seguimiento de lo hasta aquí se ha dicho, el tercer circulo que es orden valorativo, merece idéntica critica por las limitaciones que subyacen en la naturaleza de cualquier valor que no es posible llevar al plano de la exigibilidad, de no estar inscrito en las normas legales sancionadas por el poder público. De este modo, el intento epistemológico que, de inmediato es debido realizar, se visualiza en la aproximación e intersección de las tres visiones aquí explicadas de los derechos humanos para hacer que la norma esté próxima a la realidad, que las expresiones de orden fáctico permeen y se inscriban en las normas de orden positivo y que esas normas jurídicas, y la vivencia cotidiana de los derechos humanos, sean alimentadas 
invariablemente por los principios y valores que representan la gran riqueza de la dimensión axiológica de los derechos humanos.

\section{La pertinencia de la visión tetradimensional del derecho}

Como se ha dejado claro, la teoría aquí utilizada para la comprensión de los derechos humanos entraña un interesante esfuerzo epistemológico que pretende hacer la conexión entre los derechos humanos de papel, los derechos en la proyección vivencial y los derechos desde la connotación axiológica.

En este esfuerzo de reconstrucción científica, el punto de incidencia entre esta triple dimensión epistemológica permite afirmar que los derechos humanos necesitan una comprensión holística para poder atender su configuración desde el discurso y el uso del lenguaje jurídico especializado, hasta la puesta en práctica de los mecanismos legales (procesales o no) para actualizar su exigibilidad ante las diversas autoridades.

En este sentido, de manera enfática resulta necesario decir que el discurso formal sobre los derechos humanos seguirá siendo insuficiente para su garantía y que, en términos similares las expresiones de orden fáctico que pudieran contener el ejercicio de algún derecho humano, tampoco pueden ser aceptadas por el orden jurídico si no tienen un contenido que aluda a un derecho humano determinando; $v g r$., el derecho humano a disentir tiene distintos caminos para su expresión en términos de lo prescrito por el orden constitucional, sin embargo, ese derecho humano constitucionalmente reconocido, podría ser expresado en algunas otras variantes que no están previstas en la Carta Magna; en tal caso, el derecho a manifestarse o a disentir no podría configurarse como un derecho humano (desde la visión de la realidad) si deja de atender las reglas y condiciones que el propio orden jurídico señala para su ejercicio. Claro es que el ejercicio de este derecho no puede ser constitucionalmente arropado cuando el derecho humano a disentir se materializa en daño a los inmuebles o en ocupación violenta de los espacios públicos. Disentir no significa trastocar (no al menos, desde los trazos ex lege lata que el derecho positivo contiene en sus textos).

De esta afirmación, surgen las formas en que los derechos humanos de orden positivo se empalman con los modos de ejercicio de esos derechos en la vida cotidiana. En el caso citado en vía de ejemplo, parece evidente la necesaria coincidencia entre la dimensión factual de derecho humano a disentir y la prescripción normativa que lo contiene. En este orden de ideas, la tercera manifestación del derecho humano como valor, se debe entender necesariamente implícita tanto en el orden jurídico positivo que la describe, como en la conducta misma que materializa el ejercicio 
del referido derecho, con lo cual se puede aseverar que la más adecuada compresión y el más plausible desarrollo de los derechos humanos no puede concretarse ni en una visión monolítica, ni en una perspectiva bidimensional. Del argumento anterior, aflora de inmediato y con una contundencia lógica incontestable la afirmación de que los derechos humanos (desde su comprensión hasta su garantía) necesitan ser explicados y configurados en la triple dimensión teórica que aquí se viene citando.

En estos términos, una aproximación epistemológica a los derechos humanos que intente desembocar en su disfrute y apropiación cotidianos requiere indefectiblemente de las condiciones materiales, económicas y políticas claramente orientadas a la atención de cualquiera de estos derechos, cuya aprehensión siempre tendrá un costo para el Estado y la sociedad de que se trate. Esto significa que todos los derechos humanos cuestan (tienen un costo que el aparato gubernamental debe incluir en su presupuesto) y, a partir de esta realidad, la presente crítica a la concepción tridimensional de los referidos derechos consiste en afirmar que ni siquiera con la identificación de estos derechos inherentes, en el punto de intersección de la norma, el hecho y el valor, es posible declarar la viabilidad de la garantía de cualquier derecho, sin un soporte metanormativo capaz de identificar y superar las limitaciones de la realidad que imperan en cada sociedad concreta.

En el contexto aquí señalado, resulta conveniente citar el caso de algunos derechos, como la salud o la educación, que resultan poco más que buenos deseos en las sociedades más pobres y que ningún discurso formal desde la norma puede llevar más lejos, ni siquiera en el supuesto de que el orden jurídico prevea alguna acción legal para hacerlo exigible. De este modo, es fácil advertir que, si la verificación de los derechos humanos no está prevista desde el presupuesto de egresos del país concreto de que se trate, ni el discurso de las normas, ni los valores ínsitos en ellas, pueden asegurar el disfrute de derecho humano alguno.

Este es el verdadero desafío de los derechos humanos, según la perspectiva del presente abordaje. No está de más decir que, sin el adecuado andamiaje de orden material y financiero, toda la prédica y el discurso sobre los derechos humanos difícilmente dejará de ser el campo fértil para el uso perverso de las desventajas y miserias de nuestros congéneres en el discurso de la norma, en el ejercicio del poder público, en la inducción del voto a favor de determinado candidato, y en la manera como cotidianamente se nos hace creer que los gobiernos realmente trabajan para brindar seguridad, salud, educación, bienestar, y alguna posibilidad de realización humana, cierta y viable.

En términos de lo hasta aquí señalado, la construcción de la teoría tetradimensional del derecho debe tomar en consideración que toda expresión atinente al derecho 
tendrá que anudar en el futuro la cuádruple proyección de lo que entendemos por derecho, pues ninguna visión monolítica, ni siquiera bidimensional, podrá asegurar adecuadamente el disfrute de los derechos humanos.

Como se adelantó en las páginas previas, la idea de un derecho monolítico difícilmente puede operar a favor de la garantía de los derechos humanos. La explicación puede mostrarse a partir de la siguiente exposición gráfica:

\begin{tabular}{|l|l|}
\hline \multicolumn{1}{|c|}{$\begin{array}{c}\text { TIPO DE PROYECCIÓN } \\
\text { MONOLÍTICA }\end{array}$} & $\begin{array}{c}\text { LIMITACIÓN DE ESA CONCEPCIÓN } \\
\text { JURÍDICA }\end{array}$ \\
\hline Derecho como NORMA & $\begin{array}{l}\text { Derecho positivo ajeno a la realidad y } \\
\text { potencialmente injusto }\end{array}$ \\
\hline Derecho como HECHO & $\begin{array}{l}\text { "Derecho factual" carente de exigibilidad } \\
\text { yotencialmente arbitrario }\end{array}$ \\
\hline Derecho como VALOR & $\begin{array}{l}\text { "Derecho directriz" carente de fuerza } \\
\text { vinculante y posiblemente inalcanzable }\end{array}$ \\
\hline
\end{tabular}

Cuadro 1. Elaboración del autor

Como sugiere el contenido del cuadro anterior, ninguna concepción monolítica o unidimensional sirve de manera cabal al propósito de hacer que los derechos humanos se verifiquen de manera cotidiana en la vida de los habitantes.

Asimismo, tal como se señala a continuación, tampoco una proyección dual o bidimensional del derecho ayuda a garantizar a plenitud los derechos de las personas.

\begin{tabular}{|l|l|}
\hline \multicolumn{1}{|c|}{$\begin{array}{c}\text { TIPO DE PROYECCIÓN } \\
\text { BIDIMENSIONAL }\end{array}$} & \multicolumn{1}{c|}{ OBSERVACIÓN Y/O CRÍTICA } \\
\hline El derecho como NORMA-HECHO & Derecho eficaz, peligrosamente injusto \\
\hline Derecho como HECHO-VALOR & Derecho como imposición revolucionaria \\
\hline Derecho como NORMA-VALOR & Derecho ideal, desconectado de la realidad \\
\hline
\end{tabular}

Cuadro 2. Elaboración del autor

Todo parece indicar que solamente la proyección tridimensional puede asegurar los derechos, sin embargo, la realidad es otra. Son diversos los ejemplos en nuestros días que constatan la dificultad para hacer que las prescripciones normativas se materialicen en acciones concretas para el bienestar de los habitantes. Vgr., la norma que define las tareas para prevenir y erradicar la discriminación se encuentra bien elaborada; desde luego se puede mejorar; empero, tiene una definición clara de sus objetivos y su articulado no requiere mayor trabajo. La realidad en este punto patentiza la necesidad que tiene nuestra sociedad de atender este aspecto de la convivencia humana, así como también la norma contiene un valor supremo 
que es el principio de igualdad entre los seres humanos. Sin embargo, aun estando completos los tres círculos de la concepción tridimensional del derecho, ha sido posible combatir eficazmente la discriminación que sigue causando tremendo daño en la sociedad.

Desde un punto de vista propio, hace falta proyectar al derecho como acción política, como tarea de gobierno, tangible en planes y programas, así como en tareas concretas para que la discriminación pueda ser atajada desde sus primeras manifestaciones. Esta es la razón que justifica la adición de un cuarto círculo a la concepción del derecho; solamente visto así, el derecho puede trascender de su momento estático contenido en la norma -coincidente con la realidad y aherrojado en los valores- a una fase dinámica, constructiva y de mayores posibilidades de ser verificado en la vida diaria.

\begin{tabular}{|c|c|}
\hline $\begin{array}{c}\text { LA PROYECCIÓN } \\
\text { TRIDIMENSIONAL }\end{array}$ & OBSERVACIÓN Y/O CRÍTICA \\
\hline Derecho como NORMA-HECHO-VALOR & $\begin{array}{l}\text { Derecho justo, aquiescente con la realidad } \\
\text { y potencialmente verificable, pero } \\
\text { dependiente de la acción humano-social } \\
\text { contenida en la política }\end{array}$ \\
\hline
\end{tabular}

Cuadro 3. Elaboración del autor

En seguimiento a este hilo argumental, la generación de una nueva perspectiva sobre el derecho comenzará a gestar una actividad proactiva por parte del poder público, a medida que las políticas públicas y todo lo concerniente a la proyección de las tareas del Estado, asuman el compromiso cierto con la garantía de los derechos humanos. Este mismo compromiso asumido a priori para atender de manera preventiva (y no solamente remedial) el disfrute de los derechos humanos, deberá permear en las autoridades para dar cabal cumplimiento a lo que mandatan las normas de derecho positivo que, en el caso mexicano, plasma en el artículo primero de la Constitución lo siguiente: "Todas las autoridades, en el ámbito de sus competencias, tienen la obligación de promover, respetar, proteger y garantizar los derechos humanos de conformidad con los principios de universalidad, interdependencia, indivisibilidad y progresividad" (Constitución Política de los Estados Unidos Mexicanos, 1917, art.1, adicionado D.O.F. el 10 de junio de 2011). ¿Cómo cumplir con este formidable compromiso si en la vía remedial, el derecho poco alcanza a reparar el daño de las víctimas?; ¿para qué les sirve a los habitantes un sistema jurídico rico en discurso y en categorías normativas, si el gobierno no destina los recursos y tampoco desarrolla las actividades pertinentes para que los derechos humanos sean tangibles y vivenciables? 
Con total certidumbre y convencimiento, se puede afirmar que el nuevo giro epistemológico que plantea la adición de un cuarto círculo a la teoría tridimensional del derecho será el parteaguas entre los derechos humanos de papel y la acción humano-social que dotará de eficacia y certidumbre a los derechos de los habitantes. Nunca más estaremos a la espera de que una acción remedial de tipo reparador pueda devolvernos los derechos conculcados; ahora bien, la seguridad y la certeza de que nuestros derechos estarán siempre salvaguardados se gestará desde ahora en las tareas de orden profiláctico enderezadas desde el poder público que, invariablemente, contará con la participación ciudadana para la más evidente manifestación de la vida democrática y la forja de un genuino Estado constitucional.

Así las cosas, el estado de la cuestión indica la convergencia de tres proyecciones del derecho que han sido explicadas en la teoría tridimensional del derecho.

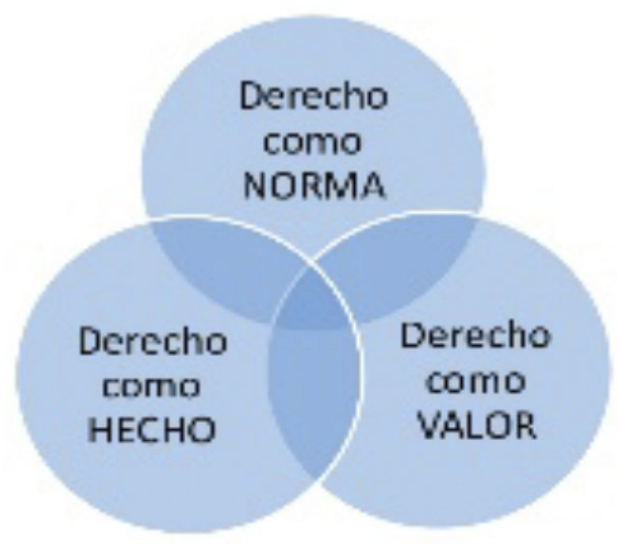

Diagrama 1. Elaboración del autor, basada en la tesis de Miguel Reale

La tesis presentada, agrega la proyección política, con la cual creemos posible un mejor desarrollo de los derechos humanos insertos en el corazón mismo de la acción estatal. Desde luego, no está de más advertir que en la adición de este cuarto círculo queda clara la connotación de la política y su proyección como acción pública, a través de lo que se conoce como las políticas públicas. Finalmente, el círculo del derecho como política, intenta visualizar la dimensión pragmática que lo jurídico debe tener en la vida de los habitantes.

Así queda este diseño tetradimensional del derecho, donde se incluyó el elemento "político" como una forma de aproximación a la vivencia del derecho, con el afán de superar las claras limitaciones que la apropiación y disfrute de los derechos humanos enfrentan en la actualidad. 


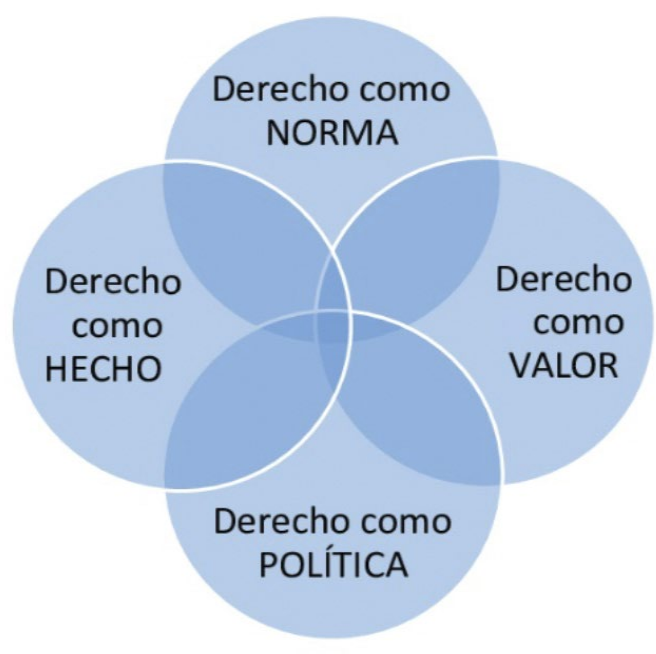

Diagrama 2. Elaboración propia del autor: Diseño de la teoría tetradimensional del derecho, propuesta por el autor

\section{Una conclusión general}

Tal como se ha podido comprender a lo largo de los párrafos anteriores, la utilidad de la concepción tridimensional del derecho que hemos proyectado al campo de los derechos humanos ha conllevado a una afirmación sobre la necesidad de concebir a los derechos humanos en esta triple proyección teórica. Sin embargo, también queda claro que, sin las condiciones de orden social, económico y político, ni aun teniendo claro el constructo teórico de los derechos humanos en la teoría tridimensional multicitada, será posible arribar a la apropiación y disfrute de estos derechos por parte de los habitantes. En otras palabras, los derechos humanos escritos en el papel necesitan de las condiciones materiales para arribar a la realidad de su disfrute por parte de los habitantes.

Como se ha mencionado:

Esto significa que los derechos humanos "de papel" que existen en todos los instrumentos internacionales y en las Constituciones deben ser replanteados en su dimensión vivencial y en los mecanismos para su aseguramiento, en ánimo de permitir la generación de escenarios que hagan viable su presencia cotidiana en todos los espacios de la vida humana. (Uribe, 2011, p. 1235)

Esta reflexión, permite introducir la idea de una teoría tetradimensional del derecho que igualmente se debe proyectar hasta los derechos humanos, con la finalidad 
de ofrecer una ruta de certidumbre a la apropiación y disfrute de los derechos humanos. Esta aproximación epistemológica, inédita, incluye un cuarto círculo que se refiere a la concepción del derecho como política, en el entendido de que la política no es -como en general se explica- la búsqueda del poder por el poder, ni siquiera la relación amigo-enemigo de corte schmittiano, sino la actividad humana encaminada a tareas cuyo propósito es atender el interés general. Evidentemente, nuestra concepción de la política aplicable al tópico que aquí exponemos no tiene que ver con el vivir de la política o vivir para la política (distinción trazada por Max Weber); la política, según el abordaje de la presente cuestión, es entendida por su relación intrínseca con la vida en comunidad, con la vida humano-social que debe potenciar las posibilidades de realización humana de los miembros de esa comunidad.

Así como señalan Herrera y Aguirre (2018):

Lo político hace referencia -en términos generales-al proceso que busca fijar las bases del orden social, es decir, a la determinación de los fundamentos sociales, a la construcción de los cimientos de una sociedad para un periodo específico, a la constitución de los principios rectores de la comunidad. (p. 1)

Incluso, es posible agregar:

Se recurre a la idea de lo político para pensar los actos instituyentes que otorgan algo más que permite movilidad o ruptura a las formaciones sociales: las posibilidades de la disputa por el sentido, de la proyección identitaria, y de cuestionar el estado de las cosas y los elementos que las sustentan. (Treviño y Tolentino, 2017, p. 12)

El derecho como política, encierra en sí mismo el derrotero de su propia natura y fines concretos. Esta visión del derecho supone afirmar que su asiento natural es el plano de la estructura y competencias de quienes pueden tomar decisiones sobre el conjunto de los habitantes. Ergo, la idea del Estado, el gobierno y las capacidades legalmente reconocidas a los órganos estatales son los conceptos fundamentales propicios para mencionar que el derecho como política necesita de esos entes que han sido diseñados y puestos en operación para querer y actuar en nombre de aquellos que los eligieron o, mejor dicho, para decidir y actuar por aquellos a quienes representan.

De esta manera, la concepción que aquí se esboza, tiene que confirmarse a partir de la aseveración de que el derecho como política es diseño y decisión que solamente pueden ser tomados desde el espacio público, lo cual significa que el cuarto 
circulo de nuestra idea tetradimensional del derecho tiene que aprehenderse en la idea de la política pública.

La expresión "políticas públicas", para efectos de este texto, será la que señalan Martínez y Arenas (2017)

Se emplea para describir tanto una forma de conducir las tareas de gobierno como un campo de conocimiento multidisciplinar sobre lo social, lo que permite analizar los estilos de gobierno, de gestión y administración pública, a la luz de las formas de organización y participación social y política. (p. 5)

En este orden de ideas, se trata de la tarea específica abocada a la identificación de las necesidades del conjunto social y a la definición de la ruta a seguir en la atención y satisfacción de esos reclamos de los y las habitantes.

A mayor abundamiento, el círculo que corresponde a la idea del derecho como actividad humana para el bien común debe aludir indefectiblemente a la proyección pragmática de ese propósito superior. En este sentido, la materialización del derecho necesita ser encaminada a través de las políticas públicas para favorecer el disfrute y garantía de los derechos de los habitantes. En vías de ejemplo podemos citar nuevamente el derecho a la educación o el derecho a la salud que, para no ser solamente discurso contenido en normas, requieren de una planeación adecuada desde el poder público y, evidentemente, en el marco de un estado democrático, de la participación de los y las habitantes.

Según Díaz (2017):

Para ser legítimas, las políticas y acciones de gobierno deben estar cada vez más ancladas en las necesidades y aspiraciones de los ciudadanos y para ser más eficaz, la hechura de las políticas públicas puede requerir la información, la colaboración, los conocimientos y la experiencia de actores no gubernamentales y de la ciudadanía en general. (p. 350)

La tarea concreta del Estado, en lo que concierne a la identificación de las necesidades y la decisión de otorgar presupuesto para su atención, es una de las más importantes para la garantía de los derechos humanos, si en verdad se desea trascender el discurso de los derechos humanos de papel y la insostenible afirmación de la prevalencia de los derechos fuera de la norma y apenas asidos a los valores -que deberíamos entender imbíbitos en cualquier derecho humano- y que, por sí mismos, no configuran ningún derecho. Así, vgr., la libertad es un valioso sustantivo que solo se convierte en el "derecho humano a la libertad" si hay una persona a quien esta deba ser reconocida. 
Dicho lo anterior, la tesis del derecho que trasciende la norma, que se vivencia en la realidad y se alimenta de principios y valores, adquiere su completitud y su versión más cercana a la vida humana cuando las actividades definidas desde el poder público tienen un enfoque indubitable hacia la realización invariable de tareas de recio contenido humanista que apuntan a la apropiación y disfrute de los derechos humanos.

Como es posible advertir, la teoría tetradimensional del derecho agrega esta proyección pragmática que necesariamente debe ser direccionada desde el poder público. Esto significa, además, que el derecho como política, es decir, los contenidos jurídicos de la actividad humano-social, necesitan el impulso y el compromiso indeclinable desde el poder público para su concreción en actividades específicas a favor de los derechos de los habitantes.

Así, esta concepción tetradimensional del derecho intenta agregar el compromiso del poder público y su necesaria vocación social, humanista y solidaria para la garantía de los derechos humanos; adicionalmente, podemos sostener que la concepción del derecho como política introduce una variación importante al concepto de garantía, en cuanto pasa de la dimensión procesal, e incluso constitucional del término, a las tareas de orden preventivo que deben tejerse desde la actividad del poder público, antes de que cualquier persona pueda optar por hacer valer sus derechos ante un tribunal. En este orden de ideas, la concepción tetradimensional del derecho permite afirmar la necesaria proyección pragmática que deben tener los derechos humanos, incluso al margen de los instrumentos legales y de los requisitos de procedibilidad que, de suyo, están plasmados en los códigos de orden procesal que prevén el ejercicio de alguna acción concreta.

Queda claro de esta forma que la visión tetradimensional aquí citada es un elemento promisorio, no solo para una mejor comprensión de los derechos humanos, sino además -y desde luego con mayor interés- para la generación de los escenarios y condiciones óptimos que permitan el disfrute de esos derechos descritos en normas, alimentados en principios y valores que muchas veces no son verificables en la realidad, pues la dimensión normativa, axiológica y las expresiones de tipo factual carecen de las condiciones materiales para su concreción en la vida cotidiana. Como se mencionó previamente, la adición de un cuarto circulo, concerniente a lo político (política y políticas públicas), complementa la concepción del derecho para llevarlo a un escenario de posibilidades reales, una vez que desde la generación de políticas públicas se diseñan los programas más adecuados y se realizan las tareas concretas para que los derechos humanos puedan ser vivenciados. 
Con este giro epistemológico, nuestro concepto de garantía sufre también una variación, como ya fue dicho, porque en su concepción amplia la garantía incluye los mecanismos que estricto sensu sirven para la exigibilidad (normalmente procesal) de un determinado derecho ante los tribunales. En este sentido, el concepto de garantía adquiere mayor plasticidad, pues será posible visualizarlo desde las políticas públicas diseñadas por el poder público para atender sin escatimación alguna, los derechos de los habitantes. De tal manera, podemos referir aquí la connotación de un concepto lato sensu de garantía que incluiría el concepto típico y ortodoxo de garantía como mecanismo procesal para el aseguramiento de un derecho concreto.

Ergo la concepción tetradimensional del derecho que aquí engarzamos con los derechos humanos agrega este cuarto circulo de lo político como acción del poder público, con el objetivo de hacer que los derechos humanos sean eficazmente garantizados, incluso antes y sin necesidad de que los y las habitantes acudan ante los tribunales. Así, podemos aceptar la siguiente afirmación: "Como la política y el arte del derecho tienen por objeto ciertas relaciones que pertenecen al orden moral-son aspectos de la realidad moral-, los principios que acabamos de recordar valen igualmente para la moral, la política y el derecho" (Hervada, 2011, p. 175).

En conclusión, se puede afirmar que esta teoría tetradimensional del derecho permite avizorar la mejor garantía de los derechos humanos, debido a que agrega las actividades del poder público, previsibles y debidamente respaldadas en presupuesto público, con la finalidad de que los derechos humanos, alimentados por principios y valores, trasciendan del discurso y se instalen en la realidad cotidiana. Es evidente que esta concepción tetradimensional del derecho, como la mejor garantía de los derechos humanos, debe de ir acompañada de un tipo de Estado caracterizado por la solidaridad y el humanismo, y un compromiso indeclinable con los más vulnerables. Así, "Los derechos humanos, entendidos como derechos de todo ser humano de todas las naciones, incluyendo los llamados "apátridas", tienen su raíz al mismo tiempo en el Estado constitucional de la actual etapa evolutiva y en la "humanidad" universal" (Haberle, 2018, p. 174). De este modo, todos los argumentos, hasta ahora defendibles sobre los derechos humanos, tendrán un mejor derrotero desde las políticas públicas del Estado constitucional, social y eminentemente humanista que toda la sociedad debe construir. 


\section{Referencias}

Bobbio, N. (1992). Teoría general del derecho. Madrid: Debate.

Camacho, D. (2016). El concepto de derechos humanos. El dilema del carácter de los derechos humanos. Revista de Ciencias Sociales (Cr), vol. II (152). Recuperado de https://www.redalyc.org/jatsRepo/153/15348419001/index.html

Constitución Política de los Estados Unidos Mexicanos (1917). Recuperado de http:// www.ordenjuridico.gob.mx/Constitucion/articulos/1.pdf)

Díaz, A. (2017). Participación ciudadana en la gestión y en las políticas públicas. Gestión y política pública, vol. XXVI (2), 341-379. México: Centro de Investigación y Docencia Económicas, División de Administración Pública. Recuperado de http://www. gestionypoliticapublica.cide.edu/ojscide/index.php/gypp/article/view/337.

García, J. (1992). Sobre los modos de conocer el Derecho: o de cómo construir el objeto jurídico, DOXA, número 11, 193-217. Alicante: Universidad de Alicante. https://doi. org/10.14198/DOXA1992.11.07

Haberle, P. (2018). El Estado constitucional. México: Instituto de Investigaciones Jurídicas, UNAM.

Herrera, H., Aguirre, J. (2018). Hacia un concepto específico de lo político. Convergencias y divergencias entre las propuestas de Schmitt y Hinkelammert, Ciencia ergo-sum, Revista Cientifica Multidisciplinaria de Prospectiva, vol. 25 (3), 1-10. México: Universidad Autónoma del Estado de México. https://doi.org/10.30878/ces.v25n3a2

Hervada, J. (2011). ¿Qué es el derecho? La moderna respuesta del realismo jurídico Navarra: Eunsa, Astrolabio.

Kahn, P. (2001). El análisis cultural del derecho. Una reconstrucción de los estudios jurídicos. Barcelona: Yale Law School, Gedisa.

Kalinowski, G. (1996). Lógica de las normas y lógica deóntica. México: Fontamara.

Lastra, M. (2002). El lenguaje jurídico y sus antinomias, Alegatos, volumen 16 (50), enero-abril 2002, 161-166. México: Universidad Autónoma Metropolitana. Recuperado de http://alegatos.azc.uam.mx/index.php/ra/article/view/721.

Marín, M. (2014). En torno a la dignidad humana como fundamento de la Declaración Universal sobre Bioética y Derechos Humanos de la UNESCO. Revista de Bioética y Derecho, núm. 31, mayo, 2014, 17-37. Barcelona: Universitat de Barcelona. https:// doi.org/10.4321/S1886-58872014000200003 
Martínez, F., Arenas, B. (2017). Política Pública de Gobierno Electrónico: El uso de las redes sociales en la juventud. Espacios Públicos, vol. 20 (50), 1-29. México: Universidad Autónoma del Estado de México. Recuperado de https:/www.redalyc.org/articulo. oa? id=67656569006.

Reale, M. (1997). Teoría tridimensional del derecho. Una visión integral del derecho Madrid: Tecnos.

Treviño. E., Tolentino, M. (2017). El lugar de lo político en el discurso de las políticas públicas. Andamios, vol. 14 (35), 99-121. México: Colegio de Humanidades y Ciencias Sociales, Universidad Autónoma de la Ciudad de México. https://doi.org/10.29092/ uacm.v14i35.573

Uribe, E. (2011). Una aproximación epistemológica a los derechos humanos desde la dimensión vivencial-pragmática. Boletín Mexicano de Derecho Comparado, número 132, 1233-1257. México: Instituto de Investigaciones Jurídicas, UNAM.

Von Wright, G. (1997). Normas, verdad y lógica. México: Fontmara. 